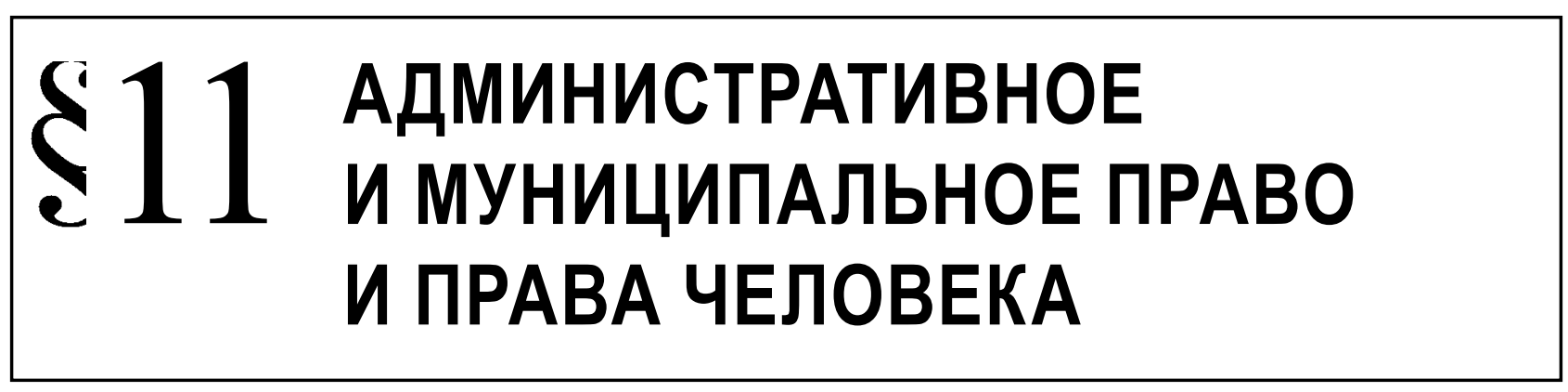

Савоськин А.B.

\title{
ВИДЫ И ОСОБЕННОСТИ ОБРАЩЕНИЙ ГРАЖДАН В ЗАВИСИМОСТИ ОТ СУБЪЕКТА ВОЛЕИЗЪЯВЛЕНИЯ
}

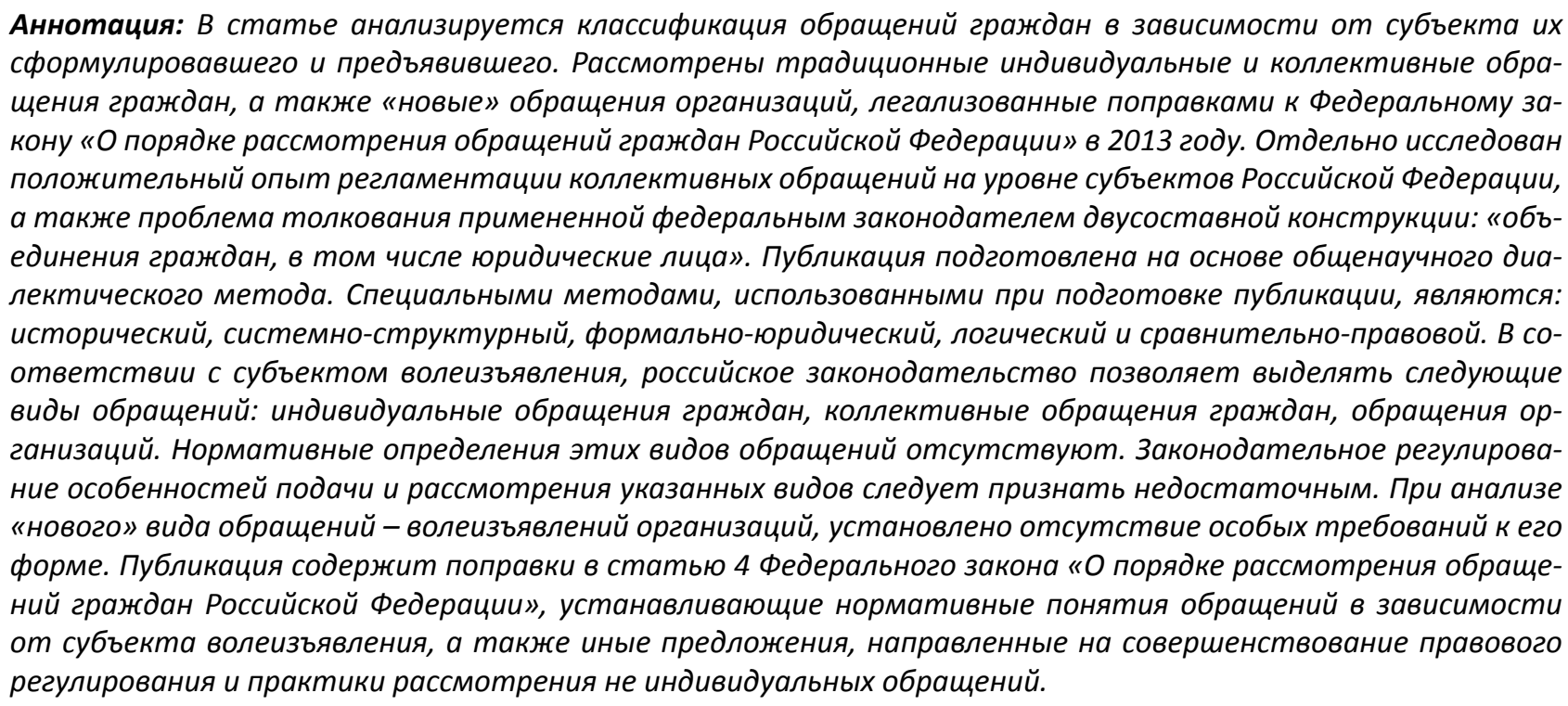
Ключевые слова: обращение, право на обращение, заявитель, индивидуальное обращение, коллективное обращение, обращение организации, обращение юридического лица, обращение объединения, законодательство об обращениях, обращение гражданина.

Review: The article analyzes the classification of citizens' appeals depending on the subject of will. The author considers the traditional individual and collective citizens' appeals, and the "new" organisations' appeals legalized by the amendments to the Federal Law "On the procedure of consideration of citizens' appeals" in 2013. The author studies the positive experience of collective appeals regulation on the local level, and the problem of explanation of the two-part construction used by the federal legislator: "citizens' associations including legal entities". The study is based on the general scientific dialectical method. The author uses the special methods: the historical method, the system-structural method, the formal-logical method, the logical and the comparative-legal method. Depending on the subject of will, Russian legislation allows separation of the following types of appeals: individual citizens' appeals, collective citizens' appeals, organisations' appeals. Normative definitions of these types are absent. Legal regulation of submission and consideration of these appeals should be declared insufficient. The analysis of the "new" type of appeals - organisations' appeals - established the absence of special submission requirements. The article provides the amendments to the article 4 of the Federal Law "On the procedure of consideration of citizens' appeals", which contain the normative definitions of appeals depending on the subject of will, and other suggestions aimed at the enhancement of legal regulation and practice of consideration of non-individual appeals.

Keywords: appeal, right to appeal, applicant, individual appeal, collective appeal, organisation's appeal, legal entity's appeal, association's appeal, legislation in the sphere of appeals, citizen's appeal. 
$\mathrm{C}$ т. 33 Конституции РФ, устанавливающая право граждан на обращение, содержит указание на индивидуальные и коллективные обращения в государственные органы и органы местного самоуправления. При этом ни Конституция, ни принятые в ее развитие федеральные законы не содержат дефиниций указанных разновидностей обращений, равно как и регламентации особенностей подачи и рассмотрения групповых волеизъявлений. Не отражает федеральное законодательство и специфики волеизъявлений «новых» субъектов права на обращение - объединений граждан и юридических лиц. Вместе с тем на практике возникает множество вопросов связанных с их рассмотрением. Например, направлять ли письменный ответ на коллективное обращение всем заявителям или только одному из них? Если одному - то кому из них? Необходимо ли прикладывать к обращению документы, подтверждающие полномочия лица подписать обращение от имени организации? Исследуем эти и другие вопросы с позиции системного подхода.

Итак, в зависимости от субъекта волеизъявления надлежит выделять: 1) индивидуальные обращения граждан; 2) коллективные обращения граждан; 3) обращения организаций. Несмотря на традиционность названных видов обращений (особенно первых двух), в юридической науке их общепринятые определения отсутствуют.

Индивидуальное обращение - это волеизъявление одного гражданина (устное или письменное), направленное одному адресату вне зависимости от количества лиц, в отношении которых предполагается наступление юридически значимых последствий. Иными словами индивидуальность или коллективность обращения зависит не от содержания, а от его формы, а именно от субъекта волеизъявления, которым при индивидуальном обращении выступает отдельный гражданин.

Термин гражданин охватывает не только лиц обладающих гражданством РФ, но и иностранных граждан и лиц без гражданства. Подобная ситуация стала возможна благодаря ч. 3 ст. 62 Конституции РФ и ст. 4 Федерального закона «О правовом положении иностранных граждан в Российской Федерации» ${ }^{1}$ согласно которым иностранные граждане и лица без гражданства пользуются в России

\footnotetext{
Федеральный закон от 25.07.2002 № 115-Ф3 (ред. от 23.07.2013) «О правовом положении иностранных граждан в Российской Федерации» // Собрание законодательства РФ. 29.07.2002. № 30. Ст. 3032.
}

правами и несут обязанности наравне с гражданами РФ, если иное не указано в законе.

В советской науке отдельные авторы, занимавшиеся проблематикой обращений граждан, утверждали: «...Хотя по существу возможность подачи жалобы иностранными гражданами у нас не ограничивается, однако, такое право никакими актами не предусмотрено...»². Аналогичный подход можно было встретить и в более поздних уже российских исследованиях. По мнению Н.Ю. Хаманевой: «Статья 33 Конституции Российской Федерации наделяет правом на обращение только граждан Российской Федерации. Вместе с тем, на практике, этим правом пользуются иностранцы и лица без гражданства...»³. «Весьма странно выглядит лишение иностранцев права на обращение при предоставлении им политического права на объединение» ${ }^{4}$.

Правильной представляется позиция Ю.Н. Алистратова: «...принцип всеобщности означает, что любое физическое лицо в соответствии с российским законодательством обладает правом на обращения в государственные органы и органы местного самоуправления за исключением случаев, установленных законом и нормами международного права. Эти изъятия касаются тех обращений, которые носят политический характер, субъектами которых выступают исключительно граждане Российской Федерации, или противоречат международно-правовым обязательствам России...» ${ }^{5}$. Аналогичной позиции придерживается И.А. Кравец, который выводит всеобщность права на обращение из принципа национального режима 6 .

Несколько иной подход предлагает С.А. Широбоков который считает, «что право обращения присуще иностранным гражданам и лицам без гражданства в отношении личных, социальных,

\footnotetext{
2 Ремнев В.И. Право жалобы в СССР. М., 1964. С.34.

Хаманева Н.Ю. Конституционное право граждан на подачу обращений // Государство и право. 1996. № 11. С.14.

4 Лейбо Ю.И., Толстопятенко Г.П., Экштайн К.А.. Научнопрактический комментарий к главе 2 Конституции Российской Федерации «Права и свободы человека и гражданина». / Под ред. К.А. Экштайна. - М.: «Издательство ЭКОМ. 2000. - С.214.

Алистратов Ю.Н. Право петиций в Российской Федерации. М.: Манускрипт, 1997. С. 39.

6 Кравец И.А. Право на обращение граждан в органы местного самоуправления: конституционные основы, проблемы регулирования и реализации // Вестник новосибирского государственного университета. Серия право. 2012. № 2. С. 36.
} 
экономических, духовных и культурных прав на основании ст. 62 п. 2, п. 3 Конституции Российской Федерации. Что же касается политических прав, то вряд ли в полной мере необходимо наделять иностранных граждан правом обращения»7.

В настоящий момент универсальные акты, устанавливающие ограничения права на обращение для не граждан РФ отсутствуют. Даже в тех случаях, когда иностранец не обладает субъективным правом, о реализации которого просит, он не лишен возможности подать соответствующее заявление, а органы власти обязаны принять обращение и дать на него пусть отрицательный, но мотивированный ответ.

2. Коллективное обращение - это волеизъявление двух и более граждан по одному предмету, сформулированное в едином документе или на личном приеме группой граждан. И Конституция России, и Федеральный закон «О порядке рассмотрения обращений граждан РФ» упоминают коллективное обращение, но не содержат его определения и не регламентируют специфики связанной с его направлением и рассмотрением, которая присутствует на практике. Указанный пробел попытались восполнить некоторые субъекты Федерации.

Так, под коллективным обращением граждан в Нижегородской области понимается письменное обращение двух и более граждан по общему для них вопросу, а также обращение, принятое на публичном мероприятии (собрании, митинге, демонстрации, шествии, пикетировании) и подписанное организатором, либо участниками публичного мероприятия, либо уполномоченным (уполномоченными) на данном публичном мероприятии лицом (лицами) $^{8}$. Похоже определение предлагает законодатель Московской области, где «коллективное обращение - обращение двух и более граждан по общему для них вопросу, а также обращение, принятое на митинге или собрании путем голосования (подписанное инициаторами коллективного обращения) или путем сбора подписей» ${ }^{9}$.

\footnotetext{
Широбоков С.А. Конституционное право человека и гражданина на обращение: Учебное пособие. Пермь. 2002. С. 18.

8 Ст. 8 Закона Нижегородской области от 07.09.2007 № 1243 (ред. от 07.04.2009) «О дополнительных гарантиях права граждан на обращение в Нижегородской области» // Правовая среда. № 66(854). 20.09.2007

9 П. 6 ст. 2 Закона Московской области от 05.10.2006 № 164/2006-О3 (ред. от 28.11.2013) «О рассмотрении обращений граждан» // Ежедневные Новости. Подмосковье. № 189. 11.10.2006.
}

Без указания на публичные мероприятия сформулировано определение в законе Алтайского края, где «коллективное обращение граждан письменное обращение в государственный орган Алтайского края, орган местного самоуправления или должностному лицу, подписанное двумя и более гражданами, а также устное обращение двух или более лиц к указанным органам или должностным лицам» ${ }^{10}$.

Пожалуй, самым подробным является определение в законе Томской области - обращение двух или более граждан по общему для них вопросу, а также обращение, принятое на собрании, конференции граждан (собрании делегатов), митинге, сходе граждан, ином публичном мероприятии, подписанное его участниками или лицом, ответственным за организацию и проведение публичного мероприятия, по поручению (решению) его участников ${ }^{11}$.

Проанализировав имеющиеся легальные определения можно заключить, что коллективным обращением является либо обращение сформулированное (и соответственно подписанное) группой граждан, либо сформулированное в ходе публичного мероприятия (возможно подписанное одним уполномоченным лицом), при этом не принципиальна внешняя форма обращения, важен сам факт выражения коллективного (тем более массового) волеизъявления.

Некоторые субъекты Федерации предусматривают дополнительные гарантии подачи и рассмотрения коллективных обращений, отсутствующие в федеральном законодательстве. Так, в Архангельской, Амурской, Томской, Саратовской и Орловской областях, а также некоторых других субъектах РФ представлены следующие однотипные гарантии: 1) письменный ответ на коллективное обращение граждан направляется лицу, указанному в обращении в качестве получателя ответа или представителя коллектива граждан, подписавших обращение; 2) если получатель ответа в коллективном обращении не определен,

10 П. 6 ст. 2 Закона Алтайского края от 29.12.2006 № 1523С (ред. от 07.10.2013) «О рассмотрении обращений граждан Российской Федерации на территории Алтайского края» // Сборник законодательства Алтайского края. № 128. Ч. 2. 2006. C. 36.

11 П. 5 ст. 1 Закона Томской области от 11.01.2007 № 5-О3 (ред. от 10.07.2013) «Об обращениях граждан в государственные органы Томской области и органы местного самоуправления» // Собрание законодательства Томской области. 31.01.2007. № 1(18). 
ответ направляется первому гражданину в списке обратившихся (подписавшихся), указавшему свой адрес места жительства; 3) в случае, если просьба о направлении ответа выражена несколькими гражданами либо всеми лицами, подписавшими коллективное обращение, копия ответа направляется каждому из них по указанным ими адресам места жительства ${ }^{12}$. В дополнение к указанным и в принципе традиционным для субъектов РФ гарантиям встречаются и иные. Например, коллективное обращение не подлежит рассмотрению только в том случае если все лица подписавшие обращение, представят заявления о прекращении рассмотрения обращения. В случае, если коллективное обращение будет отозвано одним или несколькими гражданами, то его рассмотрение продолжается в отношении оставшихся лиц ${ }^{13}$.

Интересное правило, касающееся приема коллективных обращений на личном приеме, предусмотрено в Алтайском крае. Так, должностное лицо вправе ограничить численный состав группы желающей прийти на личный прием. Делается это только в целях обеспечения безопасности граждан и с учетом технических возможностей помещения. При этом гражданам предоставлено право самостоятельно определить поименный состав лиц, которые посетят личный

12 Ст. 10 Закона Архангельской области от 15.03.2012 № 436-29-О3 (ред. от 17.10.2013) «О дополнительных гарантиях реализации права граждан на обращение в Архангельской области» // Волна. № 11, 20.03.2012 и ст. 2 Закона Амурской области от 06.07.2011 № 510-О3 «О дополнительных гарантиях права граждан на обращение в государственные органы Амурской области и органы местного самоуправления» // Амурская правда. № 123, 09.07.2011 и ст. 12 Закона Томской области от 11.01.2007 № 5-О3 (ред. от 10.07.2013) «Об обращениях граждан в государственные органы Томской области и органы местного самоуправления» // Собрание законодательства Томской области. 31.01.2007. № 1(18); ст. 5 Закона Орловской области от 02.11.2013 № 1554-О3 «О дополнительных гарантиях реализации права граждан на обращение в Орловской области» // Орловская правда. № 166, 08.11.2013; ст. 2 Закона Саратовской области от 29.07.2010 № 142-3СО «О дополнительных гарантиях права граждан на обращение в государственные органы Саратовской области и органы местного самоуправления» // Собрание законодательства Саратовской области. № 21, 07.08.2010.

13 П. 4 ст. 15 Закона Алтайского края от 29.12.2006 № 1523С (ред. от 07.10.2013) «О рассмотрении обращений граждан Российской Федерации на территории Алтайского края» // Алтайская правда. № 8-9, 18.01.2007; п. 6 ст. 5 Закон ЯмалоНенецкого автономного округа от 05.03.2007 № 24-3АО (ред. от 26.09.2013) «Об обращениях граждан» // Красный Север. № 48 (спецвыпуск № 20-21). 16.03.2007. прием ${ }^{14}$. Специальные требования к письменной форме коллективного обращения имеются в законе Курганской области ${ }^{15}$.

Возвращаясь к федеральному регулированию коллективных обращений, следует подчеркнуть, что право группового волеизъявления является универсальным правом граждан, так как это прямо следует из текста ст. 33 Конституции РФ и соответственно может быть ограничено только федеральным законом. В отличие от некоторых зарубежных государств, в России нет законов ограничивающих право коллективных обращений. Для сравнения позволим привести ст. 29 Испанской Конституции, закрепляющей право индивидуальных и коллективных обращений, в которой установлено, что военнослужащие и служащие вооруженных сил, а также военных ведомств или учреждений, подчиненных военной дисциплине, могут осуществлять право на обращение только в индивидуальном порядке и в соответствии с положениями законодательства, регулирующего их деятельность ${ }^{16}$.

3. Обращения объединений граждан как самостоятельный вид обращений появились относительно недавно, после внесения изменений в 2013 году ${ }^{17}$. Принятие поправок явилось результатом реализации правовых позиций Конституционного Суда РФ сформулированных в Постановлении от 18.07.2012 № 19-П ${ }^{18}$, Определении от

14 П. 6 ст. 15 Закона Алтайского края от 29.12.2006 № 1523С (ред. от 07.10.2013) «О рассмотрении обращений граждан Российской Федерации на территории Алтайского края» // Алтайская правда. № 8-9. 18.01.2007.

15 П. 2 ст. 3 Закона Курганской области от 06.12.2006 № 203 (ред. от 30.09.2013) «О порядке рассмотрения обращений граждан в Курганской области» // Новый мир - Документы. № 41. 14.12.2006.

16 Конституция Королевства Испании от 27 декабря 1978 г. // http://constitution.garant.ru/DOC_3864829.htm

17 Федеральный закон от 07.05.2013 № 80-Ф3 «О внесении изменений в статью 5.59 Кодекса Российской Федерации об административных правонарушениях и статьи 1 и 2 Федерального закона «О порядке рассмотрения обращений граждан Российской Федерации» // Собрание законодательства РФ. 13.05.2013. № 19. Ст. 2307.

18 Постановление Конституционного Суда РФ от 18.07.2012 № 19-П «По делу о проверке конституционности части 1 статьи 1, части 1 статьи 2 и статьи 3 Федерального закона «О порядке рассмотрения обращений граждан Российской Федерации» в связи с запросом Законодательного Собрания Ростовской области» // Собрание законодательства РФ. 30.07.2012. № 31. Ст. 4470. 
22 апреля 2004 года № 213-0 ${ }^{19}$ и некоторых других. Суд указал, что право объединений граждан, в том числе юридических лиц, обращаться в органы публичной власти производно от конституционно установленного права граждан направлять индивидуальные и коллективные обращения. Соответственно, объединениям граждан право на обращение должно быть гарантировано. Отказ в признании объединений граждан субъектами конституционного права на обращение, исходя из его предназначения как обеспечивающего осуществление других прав и свобод, свидетельствует о нарушении вытекающего из ч. 1 ст. 19 и ч. 3 ст. 55 Конституции РФ принципа равенства и справедливости.

Согласно новой ч. 4 ст. 1 Федерального закона «0 порядке рассмотрения обращений граждан РФ» «установленный настоящим Федеральным законом порядок рассмотрения обращений граждан распространяется на правоотношения, связанные с рассмотрением обращений объединений граждан, в том числе, юридических лищ». Использование двусоставной конструкции «объединения граждан, в том числе юридические лица» не случайно и соответствует российскому законодательству и позициям Конституционного Суда РФ. Необходимость введения такой правовой конструкции была вызвана двумя обстоятельствами.

Во-первых, не все объединения граждан являются юридическими лицами. Так, в соответствии с Федеральным законом «Об общественных объединениях» ${ }^{20}$ общественные объединения граждан могут создаваться и функционировать без образования юридического лица. Такие объединения (не являющиеся юридическими лицами) вправе: свободно распространять информацию о своей деятельности; проводить публичные мероприятия; представлять и защищать свои права, законные интересы своих членов и участников в органах государственной власти, органах местного

\footnotetext{
19 Определение Конституционного Суда РФ от 22.04.2004 № 213-О «По жалобе общественного благотворительного учреждения «Институт общественных проблем «Единая Европа» на нарушение конституционных прав и свобод статьями 255 и 258 Гражданского процессуального кодекса Российской Федерации и статьями 2 и 5 Закона Российской Федерации «Об обжаловании в суд действий и решений, нарушающих права и свободы граждан» // Вестник Конституционного Суда РФ. № 6, 2004.

20 Федеральный закон от 19.05.1995 № 82-Ф3 (ред. от 28.12.2013) «Об общественных объединениях» // Собрание законодательства РФ. 22.05.1995. № 21. Ст. 1930.
}

самоуправления и общественных объединениях; выступать с инициативами и вносить предложения в органы государственной власти и органы местного самоуправления; осуществлять иные полномочия в случаях прямого указания на эти полномочия в федеральных законах об отдельных видах общественных объединений (ст. 27).

Во-вторых, не все юридические лица являются формой объединения граждан. Так, в соответствии с Федеральным законом «Об обществах с ограниченной ответственностью» ${ }^{21}$ учреждение общества может осуществляться лицом единолично (п. 1 ст. 11). Также не стоит признавать органы власти, являющиеся юридическими лицами формой объединения граждан. В этом случае скорее следует вести речь об иных конституционных правах, например, праве на участии в управлении делами государства (ст. 32 Конституции РФ), но не о праве на объединение по смыслу ст. 30 Конституции РФ. В противном случае придется распространить действие Федерального закона «0 порядке рассмотрения обращений граждан РФ» на официальную переписку всех органов государственной власти и местного самоуправления между собой, что не только бессмысленно, но и вредно.

В любом случае, вне зависимости от наличия статуса юридического лица, а также от количества учредителей, все объединения граждан и все юридические лица (не являющиеся органами власти) обладают правом на обращение, а их волеизъявления мы будем именовать обращениями организации.

Основное отличие обращений организаций от двух рассмотренных выше видов обращений непосредственно граждан заключено в субъекте формулирующем и предъявляющем требование к органу власти. Если для индивидуальных или коллективных обращений - это гражданин или группа граждан, то для обращения организации, лицом уполномоченным направлять предложения, заявления и жалобы является ее представитель. Иными словами выступать от имени организации может не любой ее член, а только специально уполномоченное лицо. Представитель должен обладать полномочиями представлять организацию на основании учредительных документов, либо на основании выданной ему доверенности.

21 Федеральный закон от 08.02.1998 № 14-Ф3 (ред. от 29.12.2012) «Об обществах с ограниченной ответственностью» // Собрание законодательства РФ. 16.02.1998. № 7. Ст. 785. 
Действующий Федеральный закон «О порядке рассмотрения обращений граждан РФ» не упоминает никаких особенностей подачи и рассмотрения обращений организаций, хотя фактически они есть. Считаю, что обязательными требованиями к обращению организации должны быть: ее наименование, юридический адрес (при наличии), адрес для направления ответа, фамилия имя и отчество руководителя организации уполномоченного действовать от ее имени без доверенности. Полномочия лица подписавшего обращение организации должны подтверждаться документально.

Для сравнения ГПК РФ, прямо указывает, что к исковому заявлению в обязательном порядке прилагается доверенность или иной документ, удостоверяющие полномочия представителя истца (ст. 132). Отсутствие таких документов является основанием возвращения искового заявления (ст.135).

Вместо заключения хотелось бы предложить поправки в ст. 4 Федерального закона «0 порядке рассмотрения обращений граждан РФ», вводящие нормативные понятия обращений в зависимости от субъекта волеизъявления. А именно: «Индивидуальное обращение - это обращение, поданное от имени одного гражданина; коллективное обращение - это обращение двух и более граждан по одному вопросу, изложенное в письменной форме или сформулированное группой граждан в устной форме на личном приеме; обращение организации - это волеизъявление объединения граждан или юридического лица, изложенное в письменной форме или сформулированное на личном приеме лицом уполномоченным представлять организацию. В понятие организации в настоящем законе не включаются органы государственной власти и органы местного самоуправления».

Предлагаемые формулировки исключают любое произвольное толкование, а соответственно и возможность злоупотребления правом. Предлагаемые поправки обеспечивают абсолютное и равное право на обращение всем субъектам: гражданам, группам граждан, всем юридическим лицам (включая организации, созданные одним лицом и соответственно не являющиеся формой реализации конституционного права на объединение), а также всем объединениям граждан (вне зависимости от их регистрации в качестве юридического лица).

\section{Библиография:}

1. Алистратов Ю.Н. Право петиций в Российской Федерации. М.: Манускрипт, 1997. С. 39.

2. Кравец И.А. Право на обращение граждан в органы местного самоуправления: конституционные основы, проблемы регулирования и реализации // Вестник новосибирского государственного университета. Серия право. 2012. № 2. С. С. 36.

3. Лейбо Ю.И., Толстопятенко Г.П., Экштайн К.А.. Научнопрактический комментарий к главе 2 Конституции Российской Федерации «Права и свободы человека и гражданина». / Под ред. К.А. Экштайна. - М.: «Издательство ЭКОМ. 2000. - С.214.

4. Ремнев В.И. Право жалобы в СССР. М. 1964. С.34.

5. Савоськин А.В. О необходимости совершенствования института досудебных обращений граждан в свете правовых позиций Конституционного Суда Российской Федерации // Конституционное и муниципальное право. 2013. № 2. С. 50-54.

6. Савоськин А.В. Система обращений граждан в соответствии с объективной стороной волеизъявления граждан РФ (подсистемы устных, письменных и конклюдентных обращений) // Актуальные проблемы российского права. 2014. № 7. С. 1346-1350.

7. Савоськин А.В. Допустимо ли признавать рассмотрение обращений граждан разновидностью государственных (муниципальных) услуг? // Административное и муниципальное право. 2014. № 6. С. 574-579.

8. Х Хаманева Н.Ю. Конституционное право граждан на подачу обращений // Государство и право. 1996. № 11. С.14.

9. Широбоков С.А. Конституционное право человека и гражданина на обращение: Учебное пособие. Пермь. 2002. С. 18.

10. М.А. Липчанская Формы участия граждан в управлении делами государства в сфере исполнительной власти. // Административное и муниципальное право.-2011.-2.-С. 19-24.

\section{References (transliterated):}

1. $\quad$ Alistratov Yu.N. Pravo petitsii v Rossiiskoi Federatsii. M.: Manuskript, 1997. S. 39.

2. Kravets I.A. Pravo na obrashchenie grazhdan v organy mestnogo samoupravleniya: konstitutsionnye osnovy, problemy regulirovaniya i realizatsii // Vestnik novosibirskogo gosudarstvennogo universiteta. Seriya pravo. 2012. № 2. S. S. 36.

3. Leibo Yu.I., Tolstopyatenko G.P., Ekshtain K.A.. Nauchnoprakticheskii kommentarii k glave 2 Konstitutsii Rossiiskoi Federatsii «Prava i svobody cheloveka i grazhdanina». / Pod red. K.A. Ekshtaina. - M.: «Izdatel'stvo EKOM. 2000. - S.214.

4. Remnev V.I. Pravo zhaloby v SSSR. M. 1964. S.34. 
5. Savos'kin A.V. O neobkhodimosti sovershenstvovaniya instituta dosudebnykh obrashchenii grazhdan v svete pravovykh pozitsii Konstitutsionnogo Suda Rossiiskoi Federatsii // Konstitutsionnoe i munitsipal'noe pravo. 2013. № 2. S. 50-54.

6. Savos'kin A.V. Sistema obrashchenii grazhdan v sootvetstvii s ob"ektivnoi storonoi voleiz"yavleniya grazhdan RF (podsistemy ustnykh, pis'mennykh i konklyudentnykh obrashchenii) // Aktual'nye problemy rossiiskogo prava. 2014. № 7. S. 1346-1350.

7. Savos'kin A.V. Dopustimo li priznavat' rassmotrenie obrashchenii grazhdan raznovidnost'yu gosudarstvennykh (munitsipal'nykh) uslug? // Administrativnoe i munitsipal'noe pravo. 2014. № 6. S. 574-579.

8. Khamaneva N.Yu. Konstitutsionnoe pravo grazhdan na podachu obrashchenii // Gosudarstvo i pravo. 1996. № 11. S.14.

9. Shirobokov S.A. Konstitutsionnoe pravo cheloveka i grazhdanina na obrashchenie: Uchebnoe posobie. Perm'. 2002. S. 18.

10. M.A. Lipchanskaya Formy uchastiya grazhdan $\mathrm{v}$ upravlenii delami gosudarstva $\mathrm{v}$ sfere ispolnitel'noi vlasti. // Administrativnoe i munitsipal'noe pravo.-2011.-2.-C. 19-24. 